Document downloaded from:

http://hdl.handle.net/10251/97182

This paper must be cited as:

Franconetti Rodríguez, P.; Ortiz Bas, A. (2014). Early Warning System Potential for Single Sourcing Risk Mitigation. IFIP Advances in Information and Communication Technology. 434:610-617. doi:10.1007/978-3-662-44745-1_60

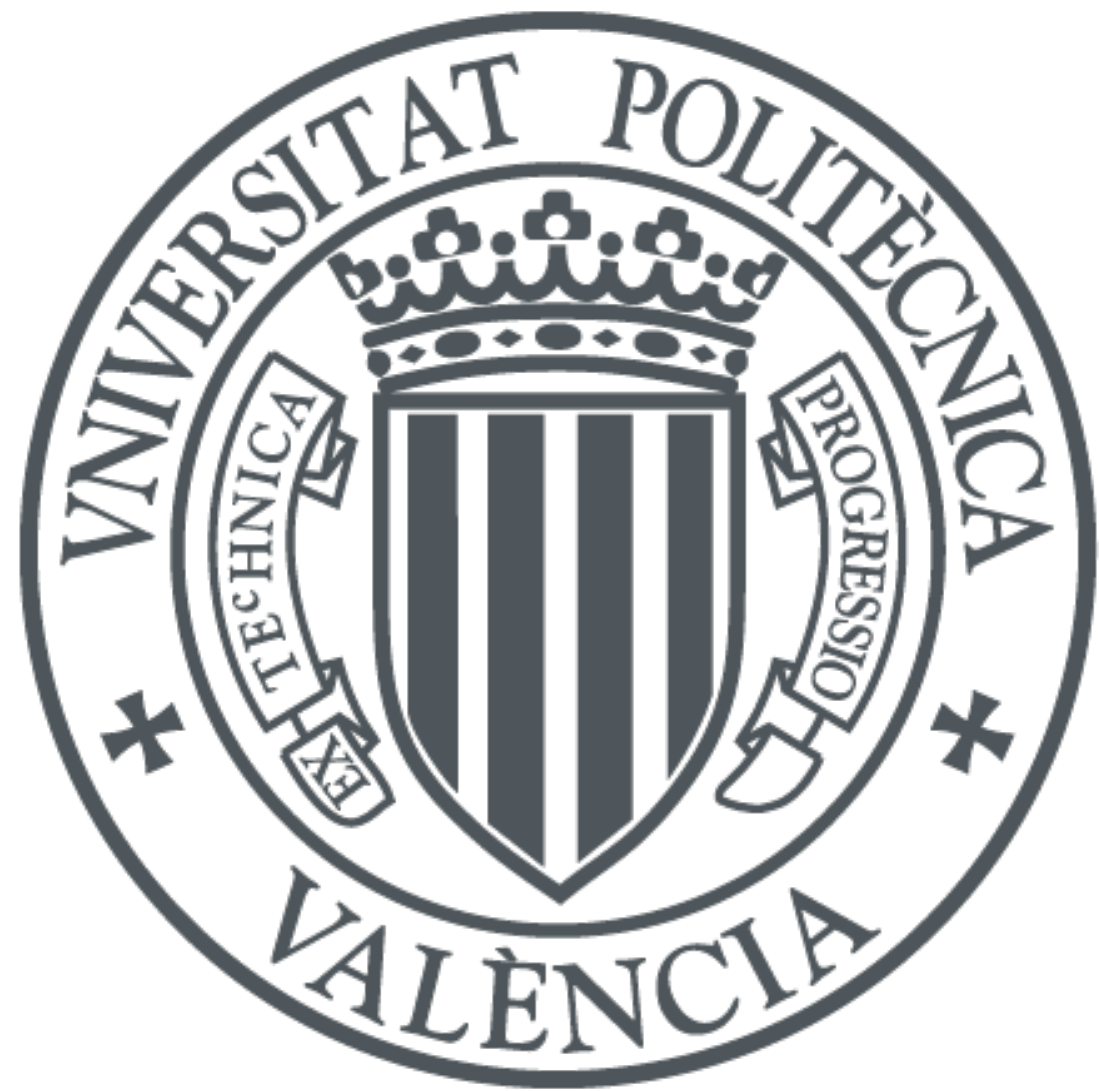

The final publication is available at

https://doi.org/10.1007/978-3-662-44745-1_60

Copyright Springer

Additional Information 


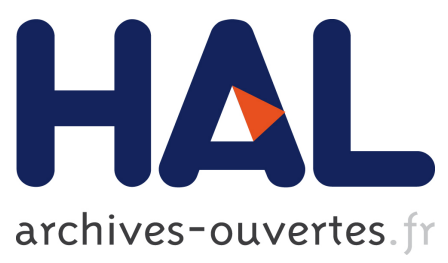

\title{
Early Warning System Potential for Single Sourcing Risk Mitigation
}

\author{
Patricia Franconetti, Angel Ortiz
}

\section{To cite this version:}

Patricia Franconetti, Angel Ortiz. Early Warning System Potential for Single Sourcing Risk Mitigation. Luis M. Camarinha-Matos; Hamideh Afsarmanesh. 15th Working Conference on Virtual Enterprises (PROVE), Oct 2014, Amsterdam, Netherlands. Springer, IFIP Advances in Information and Communication Technology, AICT-434, pp.610-617, 2014, Collaborative Systems for Smart Networked Environments. <10.1007/978-3-662-44745-1_60>. <hal-01392166>

\section{HAL Id: hal-01392166 \\ https://hal.inria.fr/hal-01392166}

Submitted on 4 Nov 2016

HAL is a multi-disciplinary open access archive for the deposit and dissemination of scientific research documents, whether they are published or not. The documents may come from teaching and research institutions in France or abroad, or from public or private research centers.
L'archive ouverte pluridisciplinaire HAL, est destinée au dépôt et à la diffusion de documents scientifiques de niveau recherche, publiés ou non, émanant des établissements d'enseignement et de recherche français ou étrangers, des laboratoires publics ou privés. 


\section{(C)(i)}

Distributed under a Creative Commons Attribution 4.0 International License 


\title{
Early Warning System Potential for Single Sourcing Risk Mitigation
}

\author{
Patricia Franconetti ${ }^{1}$ and Angel Ortiz ${ }^{2}$ \\ ${ }^{1}$ Universitat Politecnica de Valencia. C/ vera S/N, \\ 46022 Valencia, Spain. e-mail: pfranconetti@gmail.com \\ ${ }^{2}$ Centro de Investigación en Gestión e Ingeniería de Producción (CIGIP). Universitat \\ Politecnica de Valencia. C/ vera S/N, 46022 Valencia. e-mail: aortiz@omp.upv.es
}

\begin{abstract}
Network governance is described as a framework of policies and business rules, which is applied to manage an extended organization. Nowadays, one of its main concerns is risk management (RM) and the operational risk mitigation is crucial to avoid disruptions, delays and quality fades. Single sourcing can be interesting to reduce economic costs enabling the product design but at the same time can synergize the above-mentioned risks. Traditional RM approach for sourcing risks is based on selecting reliable partners, sharing knowledge and creating standard procedures that need to be complied. But the development of sensing networks based on early-warning systems (EWS) based on performance metrics to support decisions will be a promising alternative
\end{abstract}

Keywords: Risk management, governance, early warning system, performance measurement.

\section{Introduction}

Some real cases reveal that several global supply chain relationships that had begun on the premise of cost savings (e.g. offshoring or outsourcing) can be risky, not only due to natural disasters or accidents but also during the daily operation of the network. The quality problems experienced by Mattel in the sourcing of toys from China illustrate the issues [1]. In global networks, from the view of the customer-supplier relationship, the main sources of supplier risk comprise product development problems, suppliers' bankruptcy, performance loss and operational failure [2]. And it is important to remark that business structure, and especially in the case of single sourcing of important raw materials or components, the economic impact of the above-mentioned risks could be quite important. A typical practical example about the previous scenarios was a fire in one of the Philips plants that caused serious damage to its customer Ericsson, while the disruption to Nokia SC was minimal [3]. However, the risk cause should not be attributed to the structure of the network itself, the root cause is related to the management and governance. Single sourcing (SS) can enable a lean management strategy if collaboration between partners is close in order to integrate its business processes. Its benefits include cost reductions and increased 
return on assets, as well as better reliability and responsiveness to market needs [4]. But SS also exposes partners to certain vulnerabilities that must be properly managed. Product development or supplier bankruptcy can be critical risks that deserve singular risk management projects, but operational risks will immediately pose a great risk to customer firm (cost hike, quality deterioration...).

During the execution of business processes certain unexpected events happen to deviate processes from performance goals. ISO 31000 standard define risk as "the effect of uncertainty on objectives". This uncertainty, associated to each event, is determined by a combination of a pair of indicators: probability of occurrence and potential loss. After the risks assessment associated with each potential event, risk taxonomy can be created and the most damaging events are called Risk Major Events (RME). The main feature of RME is that if they occur, significant economic losses will be sure. Some typical examples of operational RME are: inventory disruption or inability to operational responsiveness. Certain previous conditions can substantially modify a RME (its occurrence and/or loss), the authors of the present work call this preconditions as Risk Triggers (RT). Some RT examples are: high rate of inventory obsolescence, a sourcing delay...Separately these preconditions can not be very important, but when they are combined or they occur previously to an RME, they could seriously affect the organization.

Supply Chain Risk Management (SCRM) traditional approach is based on periodical assessment of risks. This method is powerful but may have a reduced responsiveness when numerous risks of daily SC operations are studied. This work proposes real-time business process performance assurance methodology, based on the quality control approach [5], as a complement to improve the SCRM responsiveness. The aim is to achieve a smart governance of the network in which Early-Warning Systems (EWS) try to automatically maintain BP performance as high as possible by means of short-range measures. Furthermore, EWS has the possibility to alert the process owners when this path does not achieve the performance goal in order to prevent risk major events.

\section{Conceptualization of the Problem}

The notion of service-enhanced product brings new perspectives for value creation and differentiation in manufacturing. But complex and highly customized products and the inclusion of business services that add value to the product typically require the collaboration of multiple stakeholders. Because it is natural that each stakeholder has its own set of values and preferences and as a result, conflicts among them might emerge due to some values misalignment [6].

To understand the above-mentioned problem from an operational standpoint, the simplest configuration of a collaborative network (CN) has been studied. A single supplier and a manufacturer integrate the collaborative network. Supplier adds value to customer through processes like production or product delivering. Customers tend to assign sourcing risk to suppliers and they limit to control sourcing process performance. However this is not always true because, sometimes, customer does not properly collaborate with the supplier in defining the specifications, delivering on- 
time appropriate information and sharing risk and rewards. In this sense, an early warning system based on real-time measurement of process performance can be an excellent tool not only to prevent own risks but also to share valuable information with suppliers. Traditionally risks have been faced using the formal methodology known as "SAM". SAM is an effective multistep process in which sources of risk are identified (Specified), Assessed and Mitigated [7] but probably it can be more efficient to introduce certain aspects of smart network governance.

Risk management in collaborative networks $(\mathrm{CN})$ should be supported on three pillars see Figure 1. Network configuration analysis starts with Business Process analysis and it determines the material, financial and information flows. Synchronously, organization should try to identify the main sources of risk. But risk management is not only based on facts and data, behavioral patterns are crucial too. The organization's character (understood as a set of behaviors and organizational values like trust, loyalty and liability among partners) is the key to identify real risks for the $\mathrm{CN}$ as a whole and to apply the best solutions at the lowest cost. At the next level, using performance measurement as an integrator, network model is ready to help decision-makers not only about operations management but also to be aware about certain risks associated to specific events. Then, risk taxonomy can be build and the best performance indicator to estimate them can be defined. From this point EWS can be designed for KPI or "Key Performance Indicator" real-time monitoring and contingency plan. And EWS will alert about risks and counter-measures will be launched according with the previously established contingency plan. But fast and effective policy will be decisive to apply a continuous improvement approach in order to polish an effective contingency plan that collect the best strategies against risk.

Table 1. Cause-Effect connections found between some sourcing risk triggers and performance metrics time evolution.

\begin{tabular}{ll}
\hline \multicolumn{1}{c}{ SOURCING RISK TRIGGERS } & \multicolumn{1}{c}{ METRIC EVOLUTION } \\
\hline Inappropriate inventory level & Stock level is low/high \\
Operational/Manufacturing stoppage & Number of process breakdowns augment \\
Supplier inability to conform specifications & $\%$ Bad quality orders augment \\
Inappropriate business process resources & Capacity utilization is extremely low/high \\
High rate of material obsolescence & Cost of materials obsolescence is \\
& continuous increasing \\
Shipment disruptions or delays & $\%$ Orders/lines received on time reduction \\
\hline
\end{tabular}

This proposal can be very effective, time-efficient and fair because global decisions will be based on real data not on power relationships. During the execution of risk assessment task is when real-time performance metric monitoring can be more relevant because it could exist a connection between the risks triggers (defined by its likelihood and economic impact) and the analysis of performance metrics evolution. Our premise is EWS can detect previous events that are triggers for risk major events thus if they are detected in real-time, short-range preventive measures can be automatically launched to prevent consequences until root causes are deeply analyzed using SAM if it is a recurrent problem. 
Starting from the taxonomy proposed by Franconetti and Ortiz [8], authors have conducted a cause-effect analysis in which each trigger was analyzed in order to determine its effects and then it was thought the monitoring of what performance metric could have anticipated the consequences. Table 1 examples show how realtime performance measurement systems could help to prevent risk consequences.

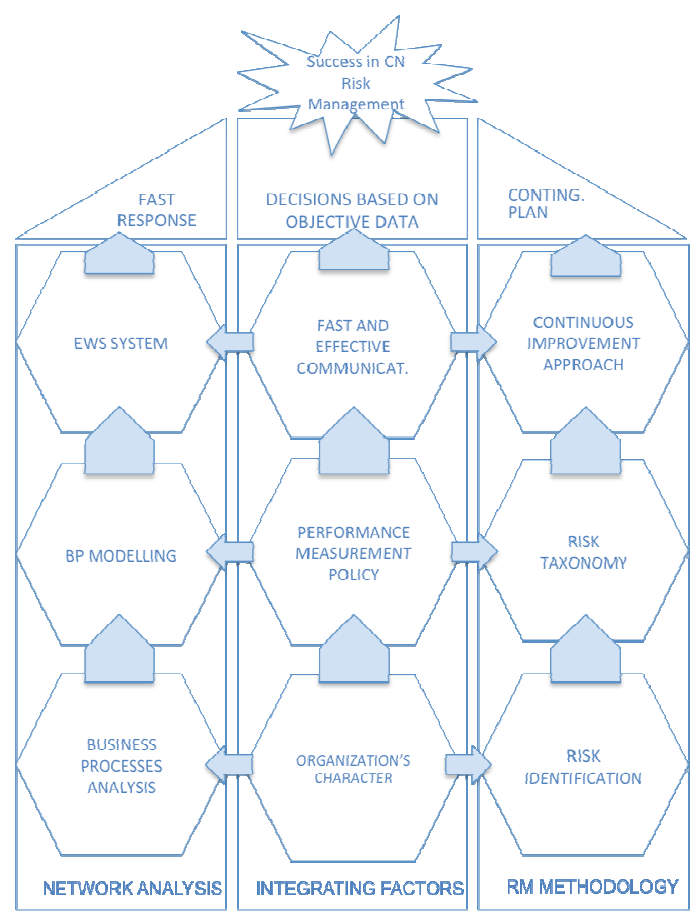

Fig. 1. Proposed approach to achieve competitive advantage using risk management

Blackhurst et al have successfully applied SAM methodology to analyze supplier's risk over time for an automotive manufacturer [9]. They use a multi-criteria scoring to calculate supplier risk indices in order to select the best option or periodically monitor the risk trends. Subjective assignation of weights to each category is used to rate them and avoid the always-unpleasant procedure of calculating occurrence probabilities. Probabilities are necessary to calculate a standard indicator of the potential loss used in SAM is known as "VAR" (value at risk). It is the product of the occurrence probability and the associated economic loss. The first drawback of this indicator is that economic loss is quite objective, but the probability must be predicted. If specific risk event likelihood is low and its inherent impact is very high, information about past decisions probably cannot predict the future, thus expert opinion and probabilistic approaches are used. The second is related to determine the VAR maximum percentage change as well as to establish the control limits that will activate the typical SAM long-range corrective actions. 
However, when the risk exposure is moderated and the predictability, based on past decisions is high, probabilistic approach can be complemented using real time performance measurement. Banks and insurance companies have designed decisions systems based on performance key risk indicators that are continuously monitored and stored in the information system for future decisions [10]. The authors of this study believe in the appropriateness of this approach for managing operational risks because information systems (like ERP) collect a lot of information about past actions. So it would be advisable to use them not only in SAM methodology but also for continuous improvement of process performance. Relevant information will help to short risk management time cycle because computational systems and the process owners will collaborate to make decisions using quantitative and trusted information.

\section{Early-Warning System based on Performance Monitoring for Risk Management}

Early-warning systems (EWS) must be based on the monitoring of reliable and representative signals from business processes. All BPs have objectives that are periodically evaluated through performance metrics measurement. There are different SC reference models, each emphasizing certain aspects considered fundamental, but most of them include key performance indicators to align processes with strategy [11]. Therefore, KPIs monitoring can be an excellent option for risk assessment. But real time data collection can be a daunting task, although with the help of Manufacturing Execution Systems (MES) this task can be greatly simplified. MES are computerized systems used in manufacturing that provide the right information at the right time. MES might operate across multiple function areas and they have modules for tracking and tracing of Overall Equipment Effectiveness (OEE) or other KPIs. The idea of MES might be seen as an intermediate step between, an Enterprise Resource Planning (ERP) system and a Supervisory Control and Data Acquisition (SCADA) [12]. Using these tools supplier and customer can simultaneously monitor KPIs and in each case the data will be recorded at their own ERP to assess its own processes. For instance, Guiledge and Chavusholu have worked in the automatic collection and integration of KPIs along the SC as enabler for process-oriented supply chain business intelligence. They have found that automated support for KPIs is feasible and achievable for the majority of ERP systems and it supposes a great advantage to make SC decisions as a whole [13]. The adoption of a reference model will guarantee the interoperability between partners thanks to information standardization. Hence it will be easier to share information and it will facilitate the understanding of the problem to the managers because all of them are familiarized with the model. 


\subsection{Business process control and automated alerts}

The optimization of EWS includes the choice of signals to be monitored, the sensitivity of the alert level and the response to these alerts. Alerts are established at a certain level of each performance metrics, they are a borderline that BP does not cross when it is under control, now it will be explained how to determine these limits.

The concept of control limit (CL) is well known in statistical chart control and it has the aim of avoiding false alerts and detecting real warnings. This is important, because BPs performance can vary due to a cloud of small events generated by chance and they must be distinguished from real threats in order to avoid random automatic actions. Therefore, process owners establish a threshold $\delta$ to each performance metric monitored $F(t)$ in order to calculate de control limit for a certain instant t like $C L(t)=F(t-1)-\delta$. If $F(t)>C L(t)$, EWS assume process is under control and no automatic preventive action is launched. In other case, EWS alert process owners in order to reduce the time to recover BP performance. This is a more efficient approach than periodical SAM execution because resources are used only when necessary to overcome specific threats. In addition, it would be interesting to enable EWS to automatically launch certain short-range preventive actions. This would convert EWS in a real smart device that collaborates with humans to reduce performance loss until SAM study will be completed.

\subsection{An example of EWS control}

A very important procurement KPI is "\% of orders on time". Periodically, collaborative network meetings define business rules and performance goals after revising the KPI trace and risk reports. However, risks triggers can appear at any time (e.g. shipment delay), probably the performance risk indicator will be affected and the process starts to move away from target (this is defined as risk). If counter measures are only applied after a fixed time period, it is probable that major event exposure (e.g. inventory disruption) will be unacceptable because time between identification and actuation is too long. Nevertheless, EWSs can be an advantage because it detects small deviations from expected target and SAM process will be just in time initiated to reduce major event risk. Example of Figure 2 represents customer sourcing KPI real time monitoring. It has been agreed with supplier a performance goal of $90 \%$ orders on time as well as a lower control limit of $75 \%$ to avoid inventory disruptions. EWS. Procurement process owner has decided EWS save the maximum performance and it will launch an automatic alert if it registers a greater deviation than $3 \%$ over the maximum. If this occurs, collaborative SAM process with the supplier will be started. Both partners will identify specific orders that are causing performance loss in their ERP system and they will seek the causes and the best solutions.

Meanwhile SAM process is executed; there is the possibility that EWS try to avoid progressive performance deterioration using short-term counter measures. This preventive actions are inside the internal operations domain, they include actions as order deferring, rerouting using the processes interoperability or buffering. Its economic cost is much less than long-range actions like process/product redesign, 
business rules modification or new partner selection [14]. So it is acceptable that short-range actions will be automatically launched by EWS to prevent risk major events. Consequences of most of risk triggers shown in Table 1, can be prevented if EWS modifies sourcing scheduled program with specific actions. Table 2 contains some examples to illustrate the concept.

Table 2. Examples of EWS automatic short-range actions that can prevent sourcing risk major events after specific warnings detected.

\begin{tabular}{cc}
\hline Warning Detected & Aim of automatic preventive action \\
\hline Stock level is very low/high & Modify security stock level of selected \\
& items \\
Number of process breakdowns augment & Rebuild workload to schedule maintenance \\
\% Bad quality orders augment & Re-scheduling poor quality orders \\
Capacity utilization is extremely low/high & Minor orders deferring \\
$\%$ Orders/lines received on time reduction & Increase sourcing time for this supplier \\
\hline
\end{tabular}

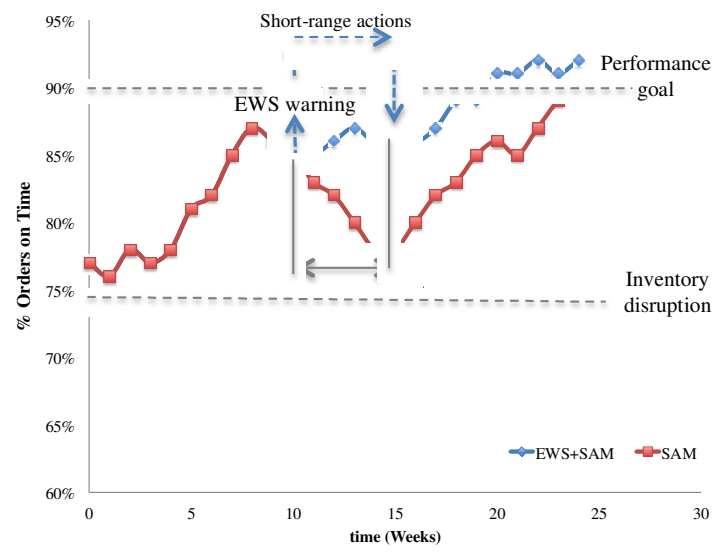

Fig. 2. Schematic representation of business process control using SAM and EWS

This work outlines the agility that can suppose this approach but there is still much work to be done. Future works will deepen the understanding of the interrelationship between the sources of risk using fault trees and the proposal of specific metrics and short-range measures for each one to be implemented in an expert system based MES+EWS tools.

\section{Conclusions}

Collaborative systems between humans and devices are interesting to overcome operational risks, improving time cycle of decision systems. However, this approach is based on quantitative information (like performance measurements) as well as a learning process to understand limitations and benefits of computational systems. 
Risk triggers interact with business processes and they affect some performance metrics. These metrics, defined as representative key performance indicators, can be a potential tool to predict future risk major events (RME) because they detect the presence of previous triggers.

Traditional approach for risk management is based on SAM methodology; it is a powerful tool, but it presents some limitations like high time cycle or complex methods to determine the risk likelihood.

Automated EWSs can complement SAM. Real time monitoring of KPIs detects small deviations from performance goal. Using quality assurance methods, shortrange preventive actions can be launched in order to avoid RME.

Information obtained from EWS is also crucial to generate risk assessment reports for risk management periodic meetings. Both parties can contrast to the opportunity cost they incurred since the last revision in order to decide a joint strategy to manage risk.

\section{References}

1. Enderwick, P.: Avoiding quality fade in Chinese global supply chains. Bus. Proc. Manag. J. 15 (6), 876-894 (2009)

2. Christopher, M., Lee H.: Mitigating supply chain risk through improved confidence, Int. J. Phys. Dist. Log. Manag, 34, 388-396 (2004)

3. Chopra, S., Sodhi, M. S.: Managing Risk to avoid Supply-Chain breakdown, MIT Sloan Manag. Rev., 53-61 (2004)

4. Zeng, A. Z.: A synthetic study of sourcing strategies, Ind. Manage Data Syst., 100(5), 219$226(2000)$

5. Wu Z., Jiao J., He Z.: A single control chart for monitoring the frequency and magnitude of an event. Int. J. Prod. Econom, 119, 24--33 (2009)

6. Camarinha-Matos L. M., Macedo P., Ferrada F., Afsarmanesh H.: Collaborative Environment for Service-enhanced Products, IFIP Adv. Inf. Com. Tech. 408,71-80 (2013)

7. Tummala, R., Schoenherr T.: Assessing and managing risks using the Supply Chain Risk Management Process (SCRMP), Suppl. Chain Manag. 16(6), 474-483 (2011).

8. Franconetti, P., Ortiz, A.: Sourcing risk management in industrial collaborative networks, IEEE T Ind Inform (under revision)

9. Blackhurst, J. V., Scheibe, K. P., Johnson D. J.: Supplier risk assessment and monitoring for the automotive industry, Int. J. Phys. Dist. Log. Manag. 38(2),143-165 (2008).

10.Scandizzo S.: Risk Mapping and Key Risk Indicators in Operational Risk Management, Ec. Notes Banca Monte dei Paschi di Siena, 34(2), 231-256 (2005).

11.Stavrulaki E., Davis M.: Aligning products with supply chain processes and strategy, Int. J. Log. Manag. 21, 127-151 (2010).

12. Chakraborty, D., Tah, D.: Real time statistical process advisor for effective quality control, Decision Support Systems, Volume 42 (2), 700-711 (2006).

13. Guiledge, T., Chavusholu T.: Automating the construction of supply chain key performance indicators, Ind. Manag. Data Syst., 108(6), 750-77 (2008).

14. Bandaly, D., Shanker, L.: Supply Chain Risk Management - II: A Review of Operational, Financial and Integrated Approaches, Risk Manag. 15,1-31 (2013). 